\title{
ChemComm
}

\section{Highly diastereoselective radical cyclisations of chiral sulfinimines $\dagger$}

Cite this: Chem. Commun., 2013, 49, 9395

Received 18th July 2013, Accepted 22nd August 2013

DOI: $10.1039 / c 3 c c 45452 e$

www.rsc.org/chemcomm

Chiral amines are formed by the highly diastereoselective intramolecular addition of alkyl and aryl radicals onto chiral mesityl sulfinimines.

Chiral amines are an important class of compounds, and find uses in the fields of drug discovery, materials synthesis and natural product synthesis. Of the many methods for the synthesis of chiral amines, ${ }^{1}$ the addition of nucleophiles to chiral sulfinimines is often the most reliable, simple and general method. ${ }^{2}$ Whilst there have been a large number of reports on the addition of anionic nucleophiles to both the Ellman tertbutanesulfinimines and Davis $p$-toluenesulfinimines, ${ }^{2}$ relatively little work has been disclosed on the use of radical addition to these motifs. Following on from a few reports throughout the past decade on their $\mathrm{SmI}_{2}$-mediated radical dimerisation or coupling with carbonyls ${ }^{3}$ and addition of cyclic etherstabilised radicals to sulfinimines, ${ }^{4}$ recently García Ruano reported the first general study on intermolecular radical addition to Ellman-type sulfiminines. ${ }^{5}$ Their study looked at addition of alkyl radicals to (mainly) aryl tert-butanesulfinyl aldimines activated by complexation with the strong Lewis-acid boron trifluoride. They showed that radical addition gave the same type of 1,2 addition products as Grignard addition, with yields in the range of $32-98 \%$ and notably high diastereoselectivity $(90 \rightarrow 96 \%$ de), although a large excess (typically 10 eq.) of alkyl iodide radical precursor was used. Prompted by this disclosure, we herein detail our preliminary investigations into the intramolecular radical reactions of chiral mesitylsulfinimines.

Our work in this area was prompted by our on-going interest in the chemistry of sulfinimines, ${ }^{6}$ and by pioneering reports by Malacria $^{7}$ and Clive ${ }^{8}$ on radical additions to imine derivatives. Clive found $O$-trityl oximes to be good substrates for radical cyclisation, whilst Malacria described a single example of

${ }^{a}$ School of Chemistry, University of Nottingham, Nottingham, NG7 2RD, UK.

E-mail: Robert.stockman@nottingham.ac.uk

${ }^{b}$ AstraZeneca, Alderley Park, Macclesfield, SK10 4TG, UK

$†$ Electronic supplementary information (ESI) available: Full experimental details. CCDC 952387-952390. For ESI and crystallographic data in CIF or other electronic format see DOI: $10.1039 / \mathrm{c} 3 \operatorname{cc} 45452 \mathrm{e}$

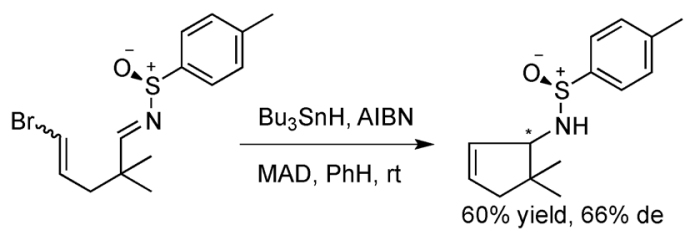

Scheme 1 Malacria's report of radical cyclisation. Absolute configuration of diastereomers was not reported.

radical addition to Davis-type $p$-toluenesulfinimines, which gave moderate diastereoselectivity in the presence of the Lewis Acid MAD (Scheme 1).

We initially decided to investigate the intramolecular radical addition of an Ellman-type tert-butylsulfinimine, as our previous work on aziridine synthesis with carbenoid-type reagents ${ }^{9}$ had shown that these larger tert-butanesulfiminines gave higher stereoselectivity than the tolyl variants (Table 1).

Thus we initially investigated the intramolecular cyclisation of compound 1a, which contained a bromide radical precursor, tethered to a tert-butanesulfinimine. After initial failure using AIBN with tributyltin hydride ${ }^{10}$ or tris(trimethylsilyl)silane, we then looked at using the aryl iodide radical precursor $\mathbf{1 b}$.

Table 1 Initial studies into radical cyclisation of sulfinimines

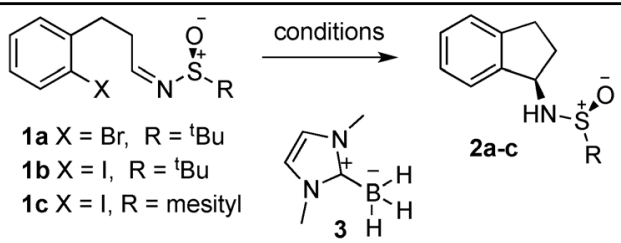

\begin{tabular}{lllllll}
\hline Entry & Substrate & Initiator & Propagator & Temp. $\left({ }^{\circ} \mathrm{C}\right)$ & Yield 2 (\%) & $\mathrm{dr}$ \\
\hline 1 & $\mathbf{1 a}$ & $\mathrm{AIBN}$ & $\mathrm{Bu}_{3} \mathrm{SnH}$ & 80 & - & - \\
2 & $\mathbf{1 a}$ & $\mathrm{AIBN}$ & $\left(\mathrm{Me}_{3} \mathrm{Si}\right)_{3} \mathrm{SiH}$ & 80 & - & - \\
3 & $\mathbf{1 b}$ & $\mathrm{AIBN}$ & $\mathrm{Bu}_{3} \mathrm{SnH}$ & 80 & - & - \\
4 & $\mathbf{1 c}$ & $\mathrm{AIBN}$ & $\mathrm{Bu}_{3} \mathrm{SnH}$ & 80 & 50 & $>98: 2$ \\
5 & $\mathbf{1 c}$ & $\mathrm{AIBN}$ & $\left(\mathrm{Me}_{3} \mathrm{Si}\right)_{3} \mathrm{SiH}$ & 80 & - & - \\
6 & $\mathbf{1 c}$ & $\mathrm{Et}_{3} \mathrm{~B} / \mathrm{O}_{2}$ & $\mathrm{Bu}_{3} \mathrm{SnH}$ & 40 & 61 & $>98: 2$ \\
7 & $\mathbf{1 c}$ & $\mathrm{AIBN}$ & 3 & 80 & 22 & $>98: 2$ \\
8 & $\mathbf{1 c}$ & $\mathrm{Et}_{3} \mathrm{~B} / \mathrm{O}_{2}$ & 3 & 40 & 33 & $>98: 2$
\end{tabular}

All reactions carried out in benzene for 2 hours. 
However, again we were not able to promote the radical cyclisation, although deiodination of the aryl iodide was observed. We thus surmised that a more electron rich sulfinimine might be more reactive towards radical addition: both Malacria and Clive's precedents used such electron rich imine derivatives. We therefore turned to mesitylsilfinimines. Initially introduced by Davis, ${ }^{11}$ we have found that they offer selectivity near that of the hindered tert-butanesulfinimines, but offer complementary reactivity in Grignard additions, giving high diastereoselectivities in an open-transition state addition. ${ }^{12}$ Furthermore, the mesityl group can be more easily removed, which can be useful for particularly sensitive substrates such as $N$-sulfinyl aziridines. ${ }^{10,11}$ We recently reported a convenient one-pot procedure for the synthesis of mesitylsulfinimines in $>99 \%$ ee using a phenyl alanine-based template, ${ }^{13}$ and thus they are also readily available substrates. It is interesting to note that this is different to the course taken by García and co-workers, who also faced the issue of low reactivity. ${ }^{5}$ Working independently to us, they instead utilised activation of the tert-butanesulfinimines with boron trifluoride in order to increase their reactivity towards radical addition, as well as using an excess of radical precursor, in their intermolecular radical addition protocol. The stereoselctivity of our radical cyclisation follows the same sense of induction as García noted, as confirmed by the X-ray crystal structure of adduct 2c (Fig. 1).

With mesitylsulfinimine 1c in hand, we then explored a range of radical initiators and propagators (Table 1 ). We were very happy to find that the mesitylsulfinimines were able to undergo radical cyclisation under a range of conditions, in each case giving the product $\mathbf{2 c}$ with complete diastereoselectivity, despite the elevated temperatures of these reactions. We were also pleased to find that tin-free conditions could be used, using the Malacria-Curran ${ }^{15} \mathrm{~N}$-heterocyclic carbene borane complex 3 as a hydrogen atom donor with either triethyl borane/oxygen or AIBN as initiator, although attempts to use the more common and commercially available tris(trimethylsilyl)silane propagator were not fruitful.

Having found success with the mesitylsulfinyl group, we then turned our attention to investigating chain length, inclusion of heteroatoms in the chain, and the use of more substituted aryl groups, heteroaryl groups, and all-alkyl systems.

Initially, we looked at inclusion of an oxygen in the tether, and the length of the tether (Scheme 2). It was found that phenol-derivative $4 a$ cyclised in similar yield to the all-carbon analogue explored previously. Increasing the chain length to form a six-membered ring (5b) also worked, albeit in slightly

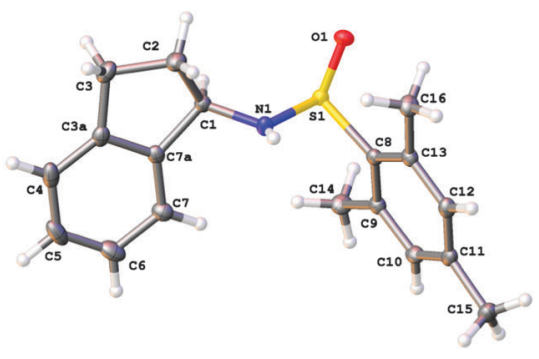

Fig. 1 X-ray crystal structure ${ }^{14}$ of $2 c$.
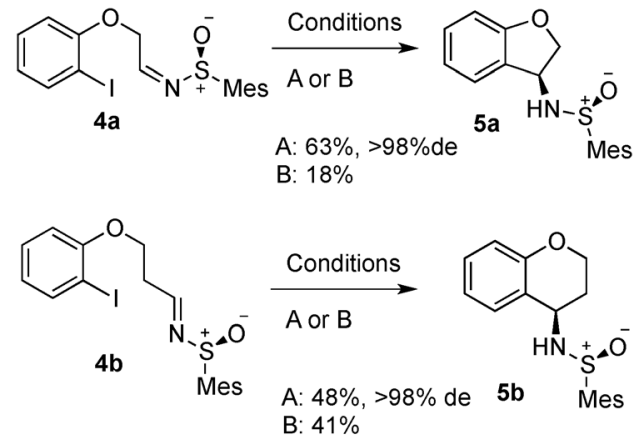

Conditions: $\mathrm{A}: \mathrm{Bu}_{3} \mathrm{SnH}, \mathrm{AIBN}, \mathrm{PhH}$, reflux

B: $\mathrm{Et}_{3} \mathrm{~B} / \mathrm{O}_{2}, \mathrm{NHC}$-borane 3, $\mathrm{PhH}, 40^{\circ} \mathrm{C}$

Scheme 2 Investigation of tether length and heteroatom inclusion.

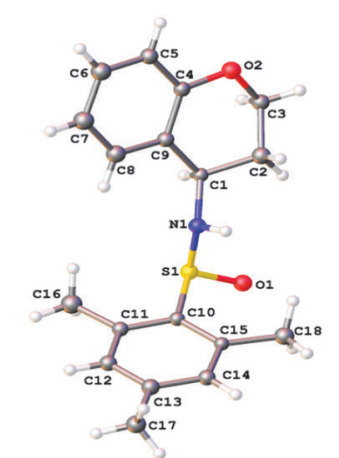

Fig. 2 X-ray crystal structure ${ }^{14}$ of $5 b$

reduced yield. The six-ring $\mathbf{5 b}$ was found to be crystalline, and thus we were able to confirm the sense of induction in the cyclisation is consistent in the formation of the five-membered ring $\mathbf{2 c}$ and the six-membered ring $\mathbf{5 b}$ system (Fig. 2). We found the mesityl sulfinimine group of $\mathbf{5 a}$ was easily removed in nearquantitative yield by treatment with $4 \mathrm{M} \mathrm{HCl}$ (Scheme 3).

We then looked at aliphatic precursors. The simple $N$-tosyl tethered system 7a was prepared, but upon reaction it was not found to undergo radical cyclisation (Scheme 4). Rather, elimination of the terminal iodide to form alkene $8 \mathbf{a}$ was observed. Cyclohexane derivative $\mathbf{7 b}$, which is not able to undergo an elimination, was successful in the cyclisation reaction, giving spirocycle $\mathbf{8 b}$ in a good $73 \%$ yield as a single diasteromer (X-ray structure, Fig. 3 ).

Finally we investigated two electron-rich aryl bromides as radical cyclisation precursors (9a and $\mathbf{9 b}$, Scheme 5). In each case, we found that the reaction was able to proceed, albeit with modest yield. No other side-products or starting material was isolated from these reactions. Both products were formed as single diastereoisomers. In the case of thiophene adduct $\mathbf{1 0 b}$, the absolute configuration was confirmed by X-ray crystallography (Fig. 4),

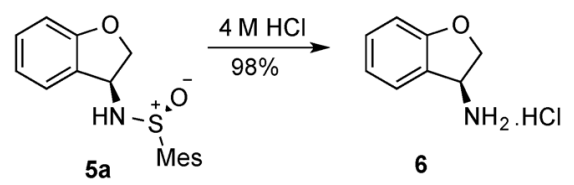

Scheme 3 Removal of mesitylsulfinyl group. 


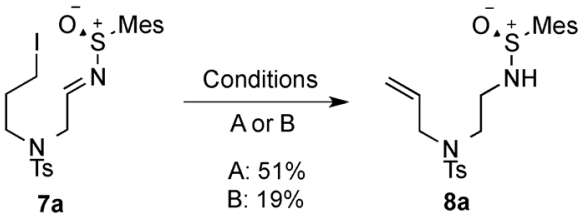<smiles>C[S+](=O)([O-])N=CCCC1(CI)CCCCC1</smiles>

Mes

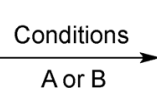

A: $73 \%$, de $>98 \%$ B: $59 \%$, de $>98 \%$

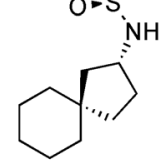

8b
Conditions: $\mathrm{A}: \mathrm{Bu}_{3} \mathrm{SnH}, \mathrm{AIBN}, \mathrm{PhH}$, reflux B: $\mathrm{Et}_{3} \mathrm{~B} / \mathrm{O}_{2}, \mathrm{NHC}$-borane $3, \mathrm{PhH}, 40^{\circ} \mathrm{C}$

Scheme 4 Investigation of aliphatic radical precursors.

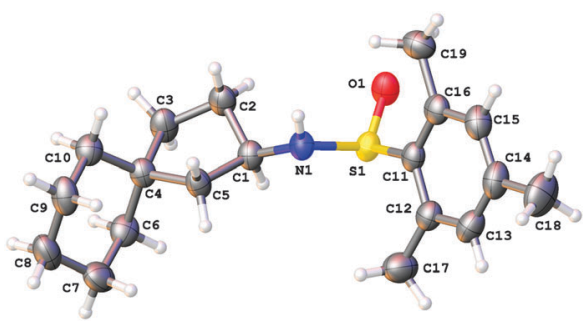

Fig. 3 X-ray crystal structure ${ }^{14}$ of $\mathbf{8 b}$. Structure shown is one of three independent molecules of compound $\mathbf{8 b}$ in the asymmetric unit.

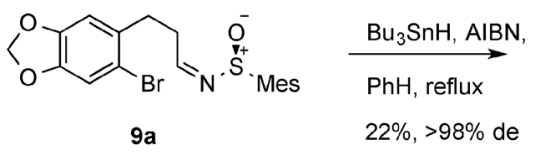

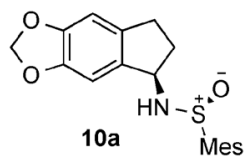
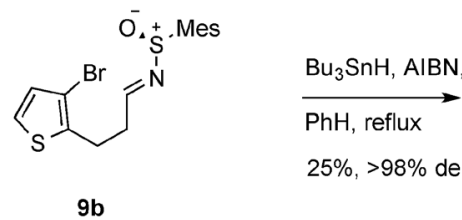

$25 \%,>98 \%$ de

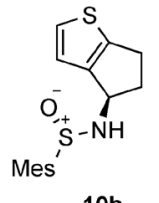

$10 \mathrm{~b}$

\section{Scheme 5 Cyclisation of electron-rich aryl bromides.}

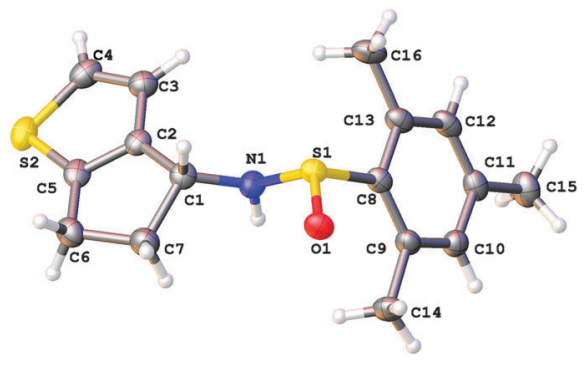

Fig. 4 X-ray crystal structure ${ }^{14}$ of $10 b$.

and we assumed the absolute stereochemistry of 10a would be that shown by analogy with $\mathbf{1 0 b}$.

In conclusion, we have found that $S$-mesitylsulfinimines are able radical acceptors, and undergo radical cyclisations with exquisite control of diastereoselectivity. The product chiral sulfinamines are easily deprotected to give chiral amines which have fused aryl/aliphatic and spiro aliphatic ring systems, making them interesting as chiral building blocks for screening collection enhancement. ${ }^{16}$ Further studies are underway in our laboratories to fully explore the scope and limitations of this unusually diastereoselective radical cyclisation methodology, which will be reported in due course.

AstraZeneca (ER) and EPSRC (RAS, EP/E055346) are acknowledged for funding.

\section{Notes and references}

1 Chiral Amine Synthesis: Developments and Applications, ed. T. C. Nugent, Wiley-VCH, Chichester, UK, 2010.

2 For a recent comprehensive review on sulfinimines in synthesis, see: M. T. Robak, M. A. Herbage and J. A. Ellman, Chem. Rev., 2010, 110, 3600. 3 B. Wang and Y. Wang, Org. Lett., 2009, 11, 3410; B. Wang and R.-H. Liu, Eur. J. Org. Chem., 2009, 2845; R. Wang, K. Fang, B.-F. Sun, M.-H. Xu and G.-Q. Lin, Synlett, 2009, 2301; R.-C. Liu, K. Fang, B. Wang, B. F. Sun, M.-H. Xu and G.-Q. Lin, J. Org. Chem., 2008, 73, 3307; R.-C. Liu, J.-H. Wei, B.-G. Wei and G.-Q. Lin, Tetrahedron: Asymmetry, 2008, 19, 2731; Y.-W. Zhong, Y.-Z. Dong, K. Fang, K. Izumi, M.-H. Xu and G.-Q. Lin, J. Am. Chem. Soc., 2005, 127, 11956.

4 T. Akindele, K. Yamada, T. Seijima, M. Maekawa, Y. Yamamoto, M. Nakano and K. Tomoika, Chem. Pharm. Bull., 2010, 58, 265; T. Akindele, Y. Yamamoto, M. Maekawa, H. Umeki, K. Yamada and K. Tomoika, Org. Lett., 2006, 8, 5729.

5 J. A. Fernández-Salas, M. C. Maestro, M. M. Rodríguez-Fernández, J. L. García-Ruano and I. Alonso, Org. Lett., 2013, 15, 1658.

6 For our most recent work in the area of sulfinimine reactivity see: G. Procopiou, W. Lewis, G. Harbottle and R. A. Stockman, Org. Lett., $2013,15,2030$.

7 E. Lacôte and M. Malacria, C. R. Acad. Sci., 1998, 191.

8 D. L. J. Clive, M. P. Pham and R. Subedi, J. Am. Chem. Soc., 2007, 129, 2713.

9 T. Moragas-Sola, I. Churcher and R. A. Stockman, Org. Biomol. Chem., 2011, 9, 5034.

10 For an excellent work-up procedure for tributyl tin hydride reactions, see: D. C. Harrowven, D. P. Curran, S. L. Kostiuk, I. L. WallisGuy, S. Whiting, K. J. Stenning, B. Tang, E. Packard and L. Nansona, Chem. Commun., 2010, 46, 6335.

11 F. A. Davis, T. Ramachandar and Y. Wu, J. Org. Chem., 2003, 68, 6894.

12 C. Roe, T. Moragas-Sola, L. Sasraku-Neequye, H. Hobbs, I. Churcher, D. MacPherson and R. A. Stockman, Chem. Commun., 2011, 4791.

13 C. Roe, H. Hobbs and R. A. Stockman, Chem.-Eur. J., 2011, 17, 2704; L. Sasraku-Neequaye, D. MacPherson and R. A. Stockman, Tetrahedron Lett., 2008, 49, 1129.

14 Ellipsoids shown at $50 \%$ probability. Crystal-data notes can be found in the ESI + .

15 A. Solovyev, S.-H. Ueng, J. Monot, L. Fensterbank, M. Malacria, E. lacôte and D. P. Curran, Org. Lett., 2010, 12, 2998; S.-H. Ueng, L. Fensterbank, M. Malacria, E. lacôte and D. P. Curran, Org. Lett., 2010, 12, 3002.

16 For interesting discussions on "Lead-Oriented-Synthesis" and three-dimensionality in screening compounds and drug discovery see: F. Lovering, MedChemComm, 2013, 4, 515; P. MacLellan and A. Nelson, Chem. Commun., 2013, 49, 2383; A. Nadin, C. Hattotuwagama and I. Churcher, Angew. Chem., Int. Ed., 2012, 51, 1114; W. P. Walters, J. Green, J. R. Weiss and M. A. Murcko, J. Med. Chem., 2011, 54, 6405; F. Lovering, J. Bikker and C. Humbler, J. Med. Chem., 2009, 52, 6752. 